\title{
Emphysematous Cystitis as Complication in Chronic Rejection of Renal Transplant
}

\author{
Erich K. Lang, Karl Zhang, Daniel Thorner, Quan D. Nguyen \\ Department of Radiology (EKL, KZ, DT, QDN), SUNY, Downstate Medical School, Brooklyn, New \\ York, USA and Johns Hopkins Medical Institutions, Bayview Center, Baltimore, Maryland, USA
}

This 43-year-old Caucasian female presented in a septic condition in the emergency room. At the time of admission her temperature was 38.5 Celsius, white blood cells (WBC) 12800, red blood cells 3.8 mill, hemoglobin 10.8 , hematocrit 36 , urea $28 \mathrm{mg} / \mathrm{dl}$, serum creatinine $3.2 \mathrm{mg} / \mathrm{dl}$, K $5.8 \mathrm{meq} / 1, \mathrm{Na} 128 \mathrm{meq} /$ 1, alk ptsa $142 \mathrm{U} / 1$. Urine analysis $50 \mathrm{WBC} / \mathrm{hpf}$, innumerable bacteria/hpf, cellular debries, gas bubbles. Both urine and later blood cultures revealed E. coli.

The lower abdomen and pelvis were exquisitely tender to palpation. Patient had been hemodialyzed 2 days earlier. Patient had received a cadavertransplant 3 years ago, which functioned well until 4 months ago. At this time chronic rejection was diagnosed. An antegrade pyelogram revealed a stricture at the implant site of the cadaver ureter, dilatation and possible ulcerations of the mid - and upper ureter. Bullous edema of the native bladder was seen, most prominent near the implant site. Immunosuppressive therapy was instituted and despite these efforts, function of the transplant kidney continued to deteriorate and the patient was finally put on hemodialysis 1 month ago. It was contemplated to perform a ureteroneo-calicostomy with the still present native ureter to hopefully salvage the kidney

A non-contrast multi-detector computed tomography demonstrated gas in the submucosa and bladder, and also extravesical anterior to the bladder (Figure-1). Strands of debries and sloughed tissue surrounded by air are seen in the bladder lumen (arrow). Gas has dissected along the anterior abdominal wall
(Figure-2). A coronal reconstruction shows relatively little striation in the perirenal space. There is edema in the peripelvic area and around the upper ureter (Figure-3).

To control the fulminating gas forming infection, bladder, transplant kidney and ureter were removed, the space of Retzius drained. Depending on the severity of the infection and underlying conditions such as diabetes mere control of the diabetes and appropriate antibiotic therapy may suffice while severe forms may mandate surgical intervention to remove the necrotic debries (1-3). After prolonged antibiotic

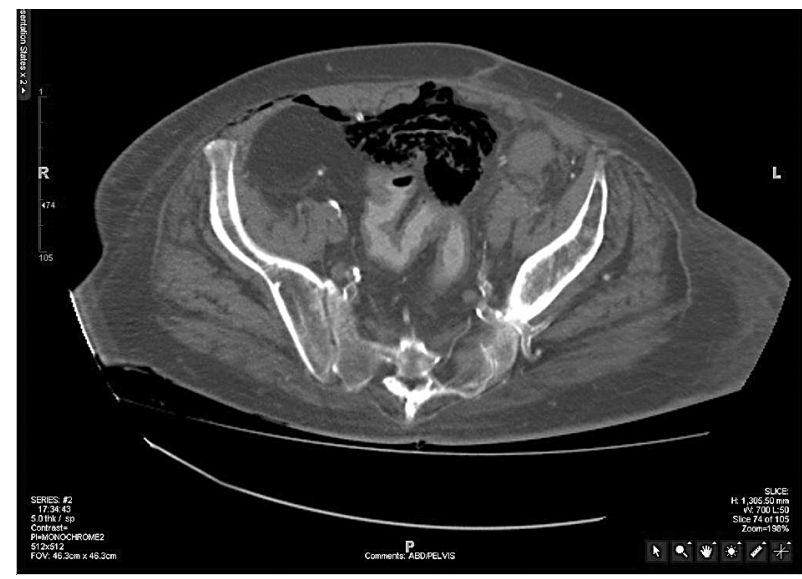

Figure 1 - A non-enhanced axial CT of the pelvis demonstrates gas in the submucosa and bladder lumen. Necrotic material and debries are outlined by gas in the bladder. An ileal loop is adherent to and indenting the bladder. Some extraluminal gas is dissecting toward the anterior abdominal wall. 


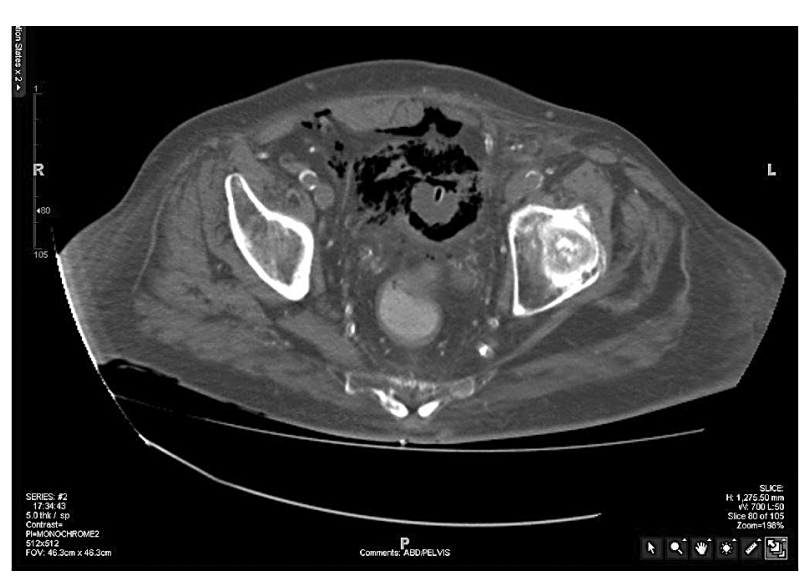

Figure 2-Gas is dissecting anteriorly into the space of Retzius and laterally toward the abdominal wall and inguinal fossa. Note tissue debries outlined by gas in the bladder and a soft tissue mass (ileal loop) indenting the bladder.

therapy and hemodialysis the patient recovered and received a second successful transplant kidney.

\section{REFERENCES}

1. Dinckan R, Tekin R, Turkyilmaz S, Kacak H, Gurkan A, Erdogen G, Tuncer M: Early and late urologic complications corrected surgically following renal transplantation. Transpl. Int. 2007; 20: 702-7.

2. Akalin E, Hyde C, Schmitt G, Kaufman J, Hamburger RJ: Emphysematous cystitis and pyelitis in a diabetic

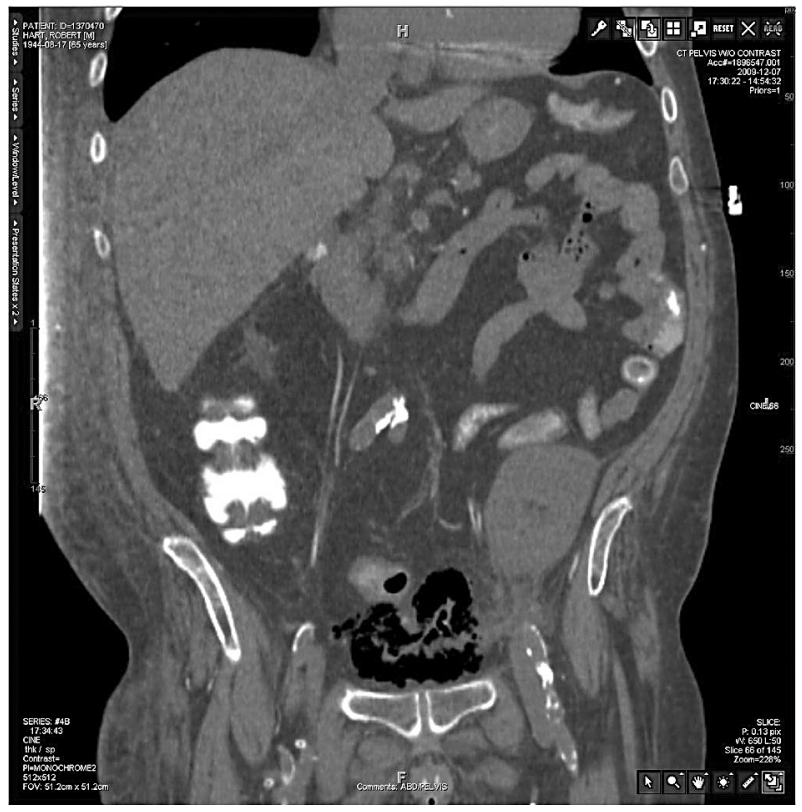

Figure 3 - A coronal reconstruction shows debries and an adherent ileal loop outlined by the gas-filled bladder. A transplant kidney is seen on the left side, with only minimal stranding in the perirenal space. However edema is seen peripelvic and periureteral space.

renal transplant recipient. Transplantation 1996; 62: $1024-6$.

3. Davavri HR, Yarmohammadi H, Malekhosseini SA, Salahi H, Bahador A, Salchipoun S: Urologic complications in 980 consecutive patients with renal transplantation. Int. J. Urol. 2006; 13: 1271-5.

\section{Correspondence address:}

Dr. Erich K. Lang

Departments of Urology and Radiology

SUNY, Downstate Health Science Center

455 Lenox Road

Brooklyn, NY, 11203, USA

E-mail: erich.lang@downstate.edu 